ISSN: 0213-2060

DOI: https://doi.org/10.14201/shhme20183611330

\title{
BAÑOS, CLAUSTROS Y PIEDRAS: UNA APROXIMACIÓN A LOS ESCENARIOS DE LAS ASAMBLEAS JUDICIALES EN LA GALICIA ALTOMEDIEVAL
}

\author{
Baths, Cloisters and Stones: An Approach to the Study of Judicial Assembly Sites \\ in Early Medieval Galicia
}

José Miguel ANDRADE CERNADAS

Depto. de Historia. Facultade de Xeografia e Historia. Universidade de Santiago de Compostela. Pza. da Universidade, 1.E-15782 SANTIAGO DECOMPOSTELA. C. e.: josemiguel.andrade@usc.es

Recibido: 2016-04-21

Revisado: 2018-04-23

Aceptado: 2018-05-18

RESUMEN: Se estudian los lugares de celebración de asambleas judiciales en la Galicia anterior al ańo 1100. Junto a lugares bien conocidos, como los monasterios e iglesias, se resalta aquí el papel jugado por villas regias y estaciones termales, así como por piedras monumentalizadas.

Palabras clave: Asamblea judicial; Villa regia; Baños; Asambleas al aire libre.

ABSTRACT: Places where judicial assemblies took place in Medieval Galicia (prior to 1100 ) are studied in this paper. Some of these meetings took place on traditional sites, such as monasteries or churches but, beside this, our attention relies upon royal villages, roman baths and monumental stones.

Keywords: Judicial Assembly; Royal Village; Baths; Open Air Assemblies.

SUMARIO: 1 Referencias bibliográficas. 
BAÑOS, CLAUSTROS Y PIEDRAS: UNA APROXIMACIÓN A LOS ESCENARIOS DE LAS ASAMBLEAS

JUDICIALES EN LA GALICIA ALTOMEDIEVAL JOSÉ MIGUEL ANDRADE CERNADAS

El interés por el estudio de la documentación de contenido judicial del período altomedieval no ha hecho sino aumentar en los últimos años ${ }^{1}$. Ciñéndonos solo al ámbito hispano, las recientes publicaciones de las monografías de Salrach ${ }^{2}$ y de Wendy Davies ${ }^{3}$ ponen de manifiesto este creciente interés sobre el tema.

Uno de los muchos aspectos tratados por la más reciente investigación en este ámbito, si bien no el más intensamente trabajado, es el de los emplazamientos de las asambleas o encuentros judiciales. Las perspectivas son bien diversas y van desde los análisis de extensos territorios, en los que se combina el trabajo arqueológico con el vaciado documental $^{4}$, hasta investigaciones realizadas sobre una parte sustancial de un reino ${ }^{5}$, por el contrario, centrándose en espacios mucho más reducidos y con un abordaje preferente desde el análisis de los documentos ${ }^{6}$.

En esta última línea pretende situarse este trabajo, cuyo objetivo fundamental es estudiar los emplazamientos o ubicaciones de las asambleas judiciales ${ }^{7}$ de la Galicia anterior al año 1100. Se trata, en definitiva, de intentar conocer la geografía de los espacios y ámbitos en los que tenían lugar las resoluciones de conflictos o, lo que es lo mismo, acercarse algo más a un mejor conocimiento de los espacios del poder en la Galicia altomedieval.

Para este fin he revisado los documentos de cuatro de los monasterios con la documentación conservada más abundante para los siglos IX-XI: Samos ${ }^{8}$, Celanova ${ }^{9}$, Sobrado ${ }^{10}$ y Lourenzá ${ }^{11}$. Los tres últimos son sendas fundaciones de grandes familias

1 Este trabajo se ha escrito en el marco de mi participación en el Proyecto de Investigación Procesos judiciales en las sociedades altomedievales. Un estudio comparativo a escala de la Europa medieval (siglos IX-XI). Plan Nacional I+D+i (Ref. 2011-26685).

2 Salrach, Josep M. a. Justícia i poder a Catalunya abans de l'any mil. Vic: Eumo, 2013.

3 Davies, Wendy. Windows on Justice in Northern Iberia, 800-1000. Farnhan: Ashgate, 2016.

4 Es, por ejemplo, el caso de los trabajos surgidos del proyecto Landscapes of Governance. (http:// www.ucl.ac.uk/archaeology/research/projects/assembly) A modo de muestra de sus publicaciones derivadas, ver BAKer, John y BRookes, Stuart. «Identifying outdoor assembly sites in early medieval England». Journal of Field Archaeology, 2015, vol. 40-41, pp. 3-21.

Carvajal Castro, Álvaro. "Meeting and meeting places in Early Medieval Leon». Early Medieval Europe, 2017, vol. 25-2, pp. 186-207. Agradezco a Álvaro Carvajal que me haya permitido conocer su trabajo antes de su definitiva publicación, al tiempo que me han sido de gran ayuda varios de sus consejos y recomendaciones.

6 Luis Corral, Fernando. «Lugares de reunión, boni homines y presbíteros en Valdevimbre y Ardón en la Alta Edad Media». Medievalista [em linha], 2015, vol. 18. Consultado los días 20 y 21 de enero del 2016.

7 Me centro, exclusivamente, en este tipo de asambleas. Dejo de lado todas las que tienen otro carácter. Sobre ellas ver CARVAJAL CASTRO, «Meeting».

8 Lucas Álvarez, Manuel. El Tumbo de San Julián de Samos (Siglos VIII-XII). Estudio introductorio, edición diplomática, apéndices e indices. Santiago de Compostela: Caixa Galicia, 1986. En adelante TS.

9 Andrade Cernadas, José Miguel. O Tombo de Celanova: estudio introductorio, edición e indices (ss. IX-XII). 2 vols. Santiago de Compostela: Consello da Cultura Galega, 1995. En adelante TC.

10 Loscertales, Pilar. Tumbos del monasterio de Sobrado de los Monjes. 2 vols. Madrid: Ministerio de Cultura, 1976. En adelante TSob

11 Rodríguez González, Ángel y Rey Caiña, José Ángel. «El Tumbo del monasterio de Villanueva de Lorenzana». Estudios Mindonienses, 1992, vol. 8, pp. 11-324. En adelante TL. 
BAÑOS, CLAUSTROS Y PIEDRAS: UNA APROXIMACIÓN A LOS ESCENARIOS DE LAS ASAMBLEAS JUDICIALES EN LA GALICIA ALTOMEDIEVAL JOSÉ MIGUEL ANDRADE CERNADAS

aristocráticas de la Galicia del siglo x y, con matices diferenciales, están muy influidos por el grupo fundador al menos en su primer siglo de existencia ${ }^{12}$. Por el contrario, Samos tiene un origen radicalmente distinto y muy anterior en el tiempo. Sus claves históricas habría que encontrarlas, al menos en estos siglos, en la relación con grupos de mozárabes procedentes de al-Andalus y en un peculiar y estrecho vínculo con la monarquía asturiana ${ }^{13}$.

En la documentación que hemos definido como de contenido judicial no siempre se hace referencia al emplazamiento o ubicación de las asambleas y encuentros judiciales ${ }^{14}$. En muchos casos, como sucede con la mayoría de las donaciones o ventas condicionadas por una intervención judicial previa, porque esa información no interesa al redactor del documento ni al fin del mismo. Se nos dice que tal o cual entrega de un bien está originada por la comisión de un delito o por una decisión judicial, pero sin hacer apenas referencia alguna al juicio en sí mismo.

Es, por ejemplo, el caso de un documento contenido en la colección de Sobrado, aunque perteneciente a lo que podríamos llamar el archivo de los condes de Présaras, Hermenegildo y Paterna ${ }^{15}$, datado en el ańo 931 y, consecuentemente, anterior a la fundación del monasterio que se produjo en el año $952^{16}$. En ese documento se nos informa que un matrimonio se ve obligado a entregar su heredad a los antedichos condes ${ }^{17}$. Se explica que su hijo Floridus había cometido un delito y estaba pendiente de juicio definitivo y, mientras tanto, sometido a una fidiatura o fianza. Para responder de ella sus padres habían acordado con los condes un plácito por el cual habrían de pagar diez bueyes en caso de que su hijo huyera antes de ser juzgado. Pese a ello se produce la huida de Floridus y, consecuentemente, los padres tienen que hacer frente a la fianza que resuelven con la carta incommuniationis que acabo de glosar. Este breve y tópico documento (hay varios contemporáneos a él que son casi idénticos) nos informa, si bien elípticamente, de al menos tres encuentros judiciales que ni siquiera se mencionan explícitamente y mucho menos se ubican.

12 Andrade Cernadas, José Miguel. «Los modelos monásticos en Galicia hasta el siglo XI». Archivo Iberoamericano, 2005, vol. 65, n. ${ }^{\circ} 252$, pp. 587-609.

13 López Alsina, Fernando. «Millas in giro ecclesie: el ejemplo del monasterio de Samos». Estudos Medievais, 1993, vol. 10, pp. 159-187. Como referencia muy reciente, ver Zwanzig, Christofer. «Heidenheim and Samos: Monastic Remembrance of the 'Anglo-Saxon Mission' in Southern Germany and the 'Mozarabic Resettlement' of Northern Spain Compared». En SÁnchez Pardo, José C. y ShaPLAND, Michael G. (eds). Churches and Social Power in Early Medieval Europe. Integrating Archaeological and Historical Approaches. Turnhout: Brepols, 2015, pp. 269-295.

14 Se trata de un hecho bastante general. Así, para el caso de León, Carvajal señala que solo en 186 documentos, de los 2.100 que son resultado de una asamblea, se hace indicación del lugar de celebración; Carvajal Castro, «Meeting».

15 Kosto, Adam J. «Sicut mos esse solet: documentary practices in Christian Iberia, c. 700-1000». En Brown, Warren C. et alii (eds.). Documentary Culture and the Laity in the Early Middle Ages. Cambridge: Cambridge University Press, 2013, pp. 259-281.

16 Pallares Méndez, M. a del Carmen. El monasterio de Sobrado: un ejemplo del protagonismo monástico en la Galicia medieval. La Coruña: Diputación Provincial, 1979, p. 71.

17 TSob, doc. 29, pp. 60-61. 
BAÑOS, CLAUSTROS Y PIEDRAS: UNA APROXIMACIÓN A LOS ESCENARIOS DE LAS ASAMBLEAS

JUDICIALES EN LA GALICIA ALTOMEDIEVAL JOSÉ MIGUEL ANDRADE CERNADAS

Por otra parte, tampoco es extraño que en documentos que tienen información judicial mucho más enjundiosa, que en el caso previamente comentado, se omitan muchos detalles concretos del proceso, entre otros, el lugar en el que se celebraron los diferentes encuentros jurídicos. Así ocurre con un documento de Celanova datado en el año 1002, en el que se recoge el pleito mantenido entre Celanova y un particular, llamado Alfonso, por la posesión de la iglesia de San Andrés de Congustro, no muy distante del monasterio celanovense ${ }^{18}$. El conflicto parece haber sido de cierta importancia. De hecho, el primer encuentro público entre las partes se produjo ante el propio niño rey Alfonso $\mathrm{V}$-casi un residente permanente en Galicia por estos ańos ${ }^{19}-\mathrm{y}$ el senatus suis de cinco jueces identificados por sus nombres. Pese a celebrarse ante tan magno tribunal, el redactor del documento no especifica el lugar en el que dicha asamblea tuvo lugar.

El documento sigue narrando las peripecias del pleito y refiere un segundo encuentro en que ambas partes aportaron sus respectivos testigos. Por cierto, siempre según el parcialísimo relato del redactor documental, Celanova presentó ni más ni menos que 356 testes ydoneos, mientras que la parte contraria acude con solo diez testigos, reputados, además, como testibus fallacissimis et negligentiosi ${ }^{20}$. Tampoco en esta ocasión se menciona el lugar en el que se produjo esta, a lo que parece, multitudinaria sesión.

El documento todavía refiere un tercer encuentro legal y público. El conde y los jueces encargados de esta fase del conflicto decidieron que un nocentem por cada una de las partes se sometiera a la ordalía de la prueba caldaria. Es el momento en que la parte enfrentada a Celanova se allana y se aviene a una agnitio que cierra el pleito ${ }^{21}$. Tampoco encontramos en el documento referencia explícita alguna a la iglesia en que se iba a celebrar la prevista y, finalmente no celebrada, ordalía, ni tampoco en dónde se produjo la ceremonia de resolución. Aunque se puede intuir que fue en el propio monasterio de Celanova en donde se celebró alguna de las vistas o encuentros jurídicos que jalonaron este conflicto ${ }^{22}$, no es menos cierto el evidente desinterés del redactor documental en aportar cualquier tipo de detalle espacial o de localización.

Pasando a los documentos judiciales que sí contienen información sobre el emplazamiento, empecemos por analizar la ubicación de las disputas presididas por el rey. Algunos de estos casos llevaron a los diferentes litigantes monásticos a presentarse en las ciudades o enclaves en los que los monarcas y sus curias solían residir la mayor parte del tiempo. De este modo, están documentadas asambleas judiciales con representación de los monjes de Celanova y de Samos en León, que era entonces la urbs regia

18 TC, doc. 252, pp. 356-358.

19 El conde gallego Menendo González fue su ayo principal durante la mayor parte de su minoría de edad. El vínculo entre ambos continuará tras la muerte del conde Menendo en 1008, ya que Alfonso V contraería matrimonio con Elvira, hija del conde galaico; ViñaYo, Antonio. Fernando I, El Magno (1035-1065). Burgos: La Olmeda, 1999, pp. 10-15.

20 TC, doc. 252, p. 357.

21 Ibidem, p. 358.

22 En las columnas de confirmantes se alude, genéricamente, a los testes in monasterio. Esto nos permite suponer que al menos algunas de estas «vistas» se celebraron en el propio cenobio celanovense, ámbito que como luego se verá, está perfectamente documentado como lugar de celebración de asambleas judiciales. 
BAÑOS, CLAUSTROS Y PIEDRAS: UNA APROXIMACIÓN A LOS ESCENARIOS DE LAS ASAMBLEAS JUDICIALES EN LA GALICIA ALTOMEDIEVAL JOSÉ MIGUEL ANDRADE CERNADAS

por excelencia ${ }^{23}$. Fuera de Galicia también están documentadas asambleas que fueron presididas por el monarca y que se celebraron en lugares como Monzón ${ }^{24}$, Burgos ${ }^{25} \mathrm{o}$ en las proximidades de la localidad berciana de Cacabelos ${ }^{26}$.

Pero, como es bien sabido, la itinerancia era el principio que marcaba el ritmo vital y la forma de entender la magistratura de los monarcas altomedievales ${ }^{27}$. Por ello y porque algunos monarcas de este período estuvieron especialmente relacionados con Galicia, no es raro encontrarse con asambleas presididas por el Rey y a las que acudieron representantes de nuestros monjes. Los lugares de Galicia en donde están documentadas son numerosos y variopintos. De esta amplia nónima, que habrá que estudiar con más detalle, se destacan tres enclaves principales.

El primero de ellos es Laias, enclave ribereño en la margen derecha del río Miño, no muy distante de Ribadavia y en las proximidades del pequeño, aunque por momentos importante, monasterio de Castrelo de Miño ${ }^{28}$. La documentación de Celanova recoge sendas asambleas que, celebradas en $995^{29}$ y $1002^{30}$ fueron presididas, respectivamente, por Bermudo II y Alfonso V. En el primero de los casos el rey parece haber estado acompañado por los obispos de Iria y Dumio, así como el propio abad de Celanova ${ }^{31}$, pero, en el segundo de los procesos, el monarca se rodea de una representación mucho más amplia y solemne. En efecto, el niño Alfonso V está acompańado por su madre, la reina Elvira, por el conde gallego Menendo González, responsable de la crianza del monarca, así como por todos los episcopos de Gallecie, simul et magnati de palatio ${ }^{32}$.

El segundo lugar especialmente representativo es Baños de Molgas, en los márgenes del río Arnoia. Otra vez es la abundante y rica documentación de Celanova la que nos informa sobre el protagonismo judicial de este enclave. La primera de las asambleas judiciales reales celebradas aquí tuvo lugar en el año $1012^{33}$ y su protagonista fue, de nuevo, Alfonso $\mathrm{V}$, cuya intensa actividad judicial está muy especialmente relacionada con Galicia ${ }^{34}$. Varias

23 TC, doc. 258, pp. 366-368; Andrade Cernadas, José Miguel. «Villas regias y asambleas judiciales entre los siglos x y xi: el caso de Larín». Signum, 2011, vol. 12, n. ${ }^{\circ}$ 2, p. 25.

24 TC, doc. 260, pp. 370-371.

25 TS, doc. 133, p. 291.

26 TL, doc. 11, p. 40.

27 Como referencia genérica, y que desborda el período altomedieval, ver Labarge, Margaret Wade. Viajeros medievales: los ricos y los insatisfechos. Madrid: Nerea, 1992, pp. 67-81. Para un ejemplo hispánico y más próximo a nuestro ámbito Reilly, Bernard F. El Reino de León y Castilla bajo el rey Alfonso VI: 1065-1109. Toledo: Consejo Superior de Investigaciones Científicas, 1989.

28 Freire Camaniel, José. El monacato gallego en la Alta Edad Media. A Coruña: Fundación Pedro Barrié de la Maza, 1998, vol. II, pp. 674-675.

29 TC, doc. 215 , pp. 304-305.

30 TC, doc. 258, pp. 366-368.

31 Sobre la evolución seguida por los integrantes de las cortes o asambleas judiciales durante el reinado de Bermudo II, ver Isla Frez, Amancio. Realezas hispánicas del año Mil. Sada-A Coruña: Ediciós do Castro, 1999, pp. 66-68.

32 TC, doc. 258 , p. 368 .

33 TC, doc. 548, pp. 756-758.

34 Fernández del Pozo, José M.a. Alfonso V (999-1028); Vermudo III (1028-1037). Burgos: La Olmeda, 1999, pp. 154-158. 
BAÑOS, CLAUSTROS Y PIEDRAS: UNA APROXIMACIÓN A LOS ESCENARIOS DE LAS ASAMBLEAS

JUDICIALES EN LA GALICIA ALTOMEDIEVAL

JOSÉ MIGUEL ANDRADE CERNADAS

décadas después, reinando Fernando I cuyo reinado trae tantas novedades y cambios, el monarca preside de nuevo un juicio que, con intereses celanovenses de por medio, se celebró en el mismo lugar y con una nutrida y selecta asistencia ${ }^{35}$.

Ambos lugares comparten algunas características comunes que podrían explicar su elección como lugar de celebración de varias asambleas judiciales con presencia y presidencia real. Se trata de dos enclaves termales que estuvieron, posiblemente, en uso desde época romana. Este origen antiguo es más probable en el caso de Molgas ${ }^{36}$ y mucho más difícil de documentar en el de Laias ${ }^{37}$. Aunque no hay plena constatación documental, ni arqueológica, parece muy probable que ambos lugares fueran conocidos y frecuentados por sus virtudes termales en la Alta Edad Media. La relativa frecuencia de visitas o residencias reales en estos enclaves podría apuntar en esa dirección ${ }^{38}$. Ambos enclaves, además, son mencionados en estos cuatro documentos como simples villae, sin referencia adicional alguna a ninguna iglesia ni monasterio. Y ello pese a la supuesta cristianización y apropiación por iglesias y monasterios medievales de los restos de la civilización romana asociada al uso y disfrute de las aguas ${ }^{39}$.

Quizá se podría ir un poco más allá en la conjetura que parece relacionar los baños con la realeza. Conviene recordar, a este respecto, que cuando la Crónica de Alfonso III, en sus dos versiones, se refiere a las construcciones acometidas por Alfonso II en su urbs regia ovetense menciona, explícitamente, que junto a la iglesia de san Julián construyó unos palacios y unos hermosos baños, empleando expresiones que parecen dar a entender que estos fuesen un complemento consustancial de aquellos ${ }^{40}$. La Crónica de Sampiro, por su parte, nos deja otra referencia que relaciona las aulas regias o palacios con baños, en este caso ya preexistentes. En la versión pelagiana, cuando el autor habla de las obras iniciativas desplegadas por Ordońo II en la ciudad de León de cara a la construcción de una nueva iglesia catedral, se dice: et intus municione muri erant tres domos, que terme fuerant paganorum, et in tempore christianitatis facte sunt aula regalis ${ }^{41}$. En este caso, las

35 TC, doc. 483, pp. 670-671.

36 González Soutelo, Silvia. El valor del agua en el mundo antiguo. Sistemas hidráulicos y aguas mineromedicinales en el contexto de la Galicia romana. A Coruña: Fundación Barrié de la Maza, 2011, p. 495.

37 Ibidem, p. 519. Aunque hay referencias a restos antiguos de apariencia romana en informes del siglo xix y se especula con posibles hallazgos, cuando se produjo la reciente construcción de un moderno balneario, el hecho de que no hubiera habido excavaciones en la zona y que un embalse ha sepultado, bajo las aguas, parte del enclave, dificulta enormemente la labor de certificar su origen romano.

38 Rodríguez Míguez, Luis. Estudio histórico bibliográfico del termalismo. Principales urgencias de la provincia de Orense. Orense: Diputación Provincial 1995, p. 145.

39 Ibidem, p. 373.

40 Nam et regia palatia, balnea, promtuaria atque uniuersa stipendia formanit et instruere precepit. Este es el texto de la versión Rotense. La versión A Sebastián, por su parte, añade otros matices, pero apuntando en la misma dirección de ver los baños como complemento del palacio regio: nam et regalia palatia, balnea, triclinia uel domata atque pretoria construxit decora et omnia regni utensilia fabrecebit pulcherrima; Gil Fernández, Juan; Moralejo Álvarez, José L. y Ruiz de la Peña, Juan Ignacio. Crónicas Asturianas. Oviedo: Universidad de Oviedo, 1985, pp. 140-141.

41 Pérez de Urbel, Justo. Sampiro. Su crónica y la monarquía leonesa en el siglo X. Madrid: Consejo Superior de Investigaciones Científicas, 1952, p. 311. 
BAÑOS, CLAUSTROS Y PIEDRAS: UNA APROXIMACIÓN A LOS ESCENARIOS DE LAS ASAMBLEAS JUDICIALES EN LA GALICIA ALTOMEDIEVAL JOSÉ MIGUEL ANDRADE CERNADAS

viejas termas romanas habrían servido como solar sobre el que edificar el palacio real dejando, de este modo, meridianamente clara la relación entre bańos y construcciones relacionadas con la monarquía ${ }^{42}$.

$\mathrm{Al}$ margen de la información cronística también encontramos vínculos entre realeza y baños en la documentación. Así, reinando Ordoño III, sabemos de la existencia de unos bańos reales en la ciudad de Zamora. Así lo indica el documento por el que este monarca hace donación al monasterio de Celanova de una aceña qui est sita sub balneos nostros in flumen Durio, in Camora ${ }^{43}$.

Parece, en consecuencia, que se puede admitir la relación entre baños o estaciones termales y la monarquía de esta época ${ }^{44}$; y ello nos lleva a plantearnos, de nuevo, las asambleas judiciales presididas por los reyes en Laias y Molgas. De la lectura de los documentos que las refieren podemos extraer la idea del carácter eminentemente «civil», si se me permite el anacronismo, de estos emplazamientos que, aunque no son identificados como villas regias, ni como palatia ${ }^{45}$, pueden entenderse, por las razones que acabamos de exponer, como muy conectadas con los monarcas de León.

Sí es mencionada como villa regia, por el contrario, la localidad de Larín. Se trata de uno de los enclaves más veces mencionados como emplazamiento de asambleas judiciales presididas por el rey o en donde se trataban casos que afectaban al realengo. Se sitúa en

42 Sánchez-Albornoz atribuye a Ordoño I la construcción del palacio regio sobre las termas que, aclara, eran romanas tal y como se evidenciaría por los hallazgos, realizados a fines del siglo XIX, de dos hipocaustos y un mosaico con motivos marinos; SÁnchez-Albornoz, Claudio. Una ciudad de la España cristiana hace mil años. 14. ${ }^{a}$ ed. Madrid: Rialp, 1991, pp. 23-24 y 27. Gutiérrez González y Miguel Hernández sugieren que las termas pudieron haber sido aún visibles en el siglo ix y que esto habría propiciado la construcción del palacio regio en esa zona; GutiérRez GonZÁLez, José Avelino y Miguel Hernández, F. «Génesis del urbanismo en la ciudad de León y su transformación en la Edad Media». En VALDÉs FerNÁNDEZ, Fernando (coord.). La Peninsula Ibérica y el Mediterráneo entre los siglos XI y XII. El urbanismo de los estados peninsulares. Aguilar de Campoo: Fundación Santa María la Real, 1999, p. 55.

Posteriormente, Ordońo II, cedería este palacio real para la construcción de una nueva iglesia catedral.

43 TC, doc. 426, p. 586.

44 No me corresponde, al menos aquí y ahora, dar una explicación satisfactoria de esta relación. Además de tener en cuenta ejemplos que podrían servir de inspiración, como el de Carlomagno con sus baños de Aquisgrán, o un posible influjo de la cultura andalusí y de sus palacios, habría que verlo como una reutilización más del legado cultural y arquitectónico romano (sobre el que tanto se ha escrito) entendido, en este caso, en una dimensión especialmente simbólica y política. Es decir, podría ser una suerte de guiño que conectaría a los reyes altomedievales con el glorificado y prestigiado pasado romano.

45 Sobre los palatia, reales y de otras titularidades, ver, entre otros, GarCía de CoRTÁzAR, José Ángel y PeÑA Bocos, Ester. «El palatium, símbolo y centro de poder en los reinos de Navarra y Castilla a lo largo de los siglos x a XII». Mayurqa, 1989, vol. 22, n. ${ }^{\circ}$ 1, pp. 281-296; y Escalona Monge, Julio y MARTín Viso, IÑAKI. «Los palatia, puntos de centralización de rentas en la meseta del Duero (siglos IX-XI)». En Vigil-Escalera Guirado, Alfonso; Bianchi, Giovanna y Quirós Castillo, Juan Antonio (eds.). Horrea, barns and silos. Storage and incomes in Early Medieval Europe. [Bilbao]: Universidad del País Vasco, 2013, pp. 103-126.

El uso del término palatia parece haber sido poco usado en la documentación del Noroeste peninsular, en especial en la época que estudiamos; Varela SieIro, Xaime. Léxico cotián na alta Idade Media de Galicia: a arquitectura civil. Santiago de Compostela: Universidade de Santiago de Compostela, 2008, pp. 179-182; Marques, André Evangelista. Da representaçáo documental a materialidade do espaço. Território da diocese de Braga (séculos IX-XI). Porto: Ediçóes Afrontamento, 2014, pp. 305-306. 
BAÑOS, CLAUSTROS Y PIEDRAS: UNA APROXIMACIÓN A LOS ESCENARIOS DE LAS ASAMBLEAS JUDICIALES EN LA GALICIA ALTOMEDIEVAL JOSÉ MIGUEL ANDRADE CERNADAS

las proximidades del monasterio de San Julián de Samos, en cuya documentación está muy bien atestiguada, y en un territorio en que los monarcas astures y, posteriormente, los leoneses tienen sólidos intereses patrimoniales ${ }^{46}$.

Son tres las asambleas judiciales celebradas en este lugar según la documentación samonense. A las dos de finales del siglo x (960 y 985, respectivamente) hay que añadirle una última celebrada en 1074, reinando ya Alfonso VI. A estos encuentros judiciales hay que añadir una cuarta asamblea que podemos documentar gracias a la colección diplomática de Lourenzá. Se trata del pleito que enfrenta al entonces infante don García, futuro rey de Galicia, con el obispo mindoniense don Suero a propósito de la herencia de la condesa doña Elvira $^{47}$. El primero de los dos encuentros públicos entre estas dos partes enfrentadas se produjo «in concilio» ante rex dompno Fredenando et magnatii palatii... hic in Elarim ${ }^{48}$.

Lo interesante de este enclave es que, además de servir como escenario de cuatro asambleas judiciales de especial consideración, mantuvo una especialísima relación «funcionarial» con la monarquía leonesa, ya que a lo largo de los reinados de Alfonso VI y de doña Urraca, cuando menos, sirvió como lugar de residencia de diferentes representantes del poder real como vicarios reales, condes o merinos ${ }^{49}$.

En el actual Larín, una pequeñisima y raramente compacta parroquia, no queda rastro alguno de las construcciones que pudo haber habido en aquella villa real, escenario de esas diversas asambleas judiciales entre los siglos $\mathrm{x}$ y XI que acabamos de mencionar. La importancia de este lugar estriba principalmente en que nos permite recordar algo que la documentación solo refleja tímida y esporádicamente, casi como sin querer, como si fuese un lapsus calami más del transcriptor del documento: la presencia física del rey y del poder regio en la Galicia altomedieval ${ }^{50}$. Tema complejo y difícil, pero completamente necesario, para tener una visión mucho más perfilada y pertinente de la realidad galaica en estos siglos. Dicho de otro modo, la omnipresencia de la documentación monástica nos puede hacer imaginar una Galicia que hubiera sido un inmenso coto propiedad de los monjes, algo que, a ciencia cierta, nunca pudo haber sido por más que la documentación de la que disponemos nos pueda transmitir esa imagen.

Dejando de lado los casos en que está documentada la intervención del rey, otro de los emplazamientos preferentes en los conflictos, en especial en aquellos que enfrentaban a diferentes integrantes de las élites sociales, eran las iglesias ${ }^{51}$, en especial las más representativas y prestigiosas y, de manera particular, las iglesias episcopales.

46 Andrade Cernadas, «Villas regias».

47 TL, doc. 11, pp. 40-41.

48 Ibídem, p. 40. Los editores unieron la preposición con el nombre del lugar quedando la transcripción del documento de este modo poco comprensible: hic inelarim.

49 Andrade Cernadas, «Villas regias».

50 Palacios de la Valduerna, sede de dos asambleas regias, es uno de los lugares que, en León, puede haber jugado un papel semejante al de Larín en Galicia; cfr. Carvajal CaStro, «Meeting». Sobre este mismo enclave, como palacio y nodo de una red de propiedades regias en León, ver Escalona Monge y Martín Viso, «Los palatia», pp. 116-117.

51 Sobre el papel principal jugado por las iglesias rurales como lugares de reunión y de asambleas (también judiciales) ver Salrach, Justícia, p. 31; Luis Corral, «Lugares». De modo muy especial Carvajal Castro, «Meeting». 
BAÑOS, CLAUSTROS Y PIEDRAS: UNA APROXIMACIÓN A LOS ESCENARIOS DE LAS ASAMBLEAS JUDICIALES EN LA GALICIA ALTOMEDIEVAL JOSÉ MIGUEL ANDRADE CERNADAS

El peso de estas iglesias en el complejo sistema procesal de esta época es fácil de comprender. Partes del mismo, como los juramentos, tenían que celebrarse, necesariamente, en recintos eclesiásticos y cuanto más significativo fuese el templo podría considerarse que sería como si el juramento ganase un plus de ritualidad y sacralidad. Los obispos, además, solían desempeñar funciones de tipo jurisdiccional, por no hablar de su interrelación con las grandes estirpes condales y con los monarcas. Por último, y como argumento que en estos siglos hay que considerar de menor importancia, habría que valorar el hecho de que los obispos sean cabezas visibles de un territorio diocesano, bajo cuya autoridad tienen que dilucidarse no pocos de los conflictos que se generan entre las instituciones eclesiásticas pertenecientes al mismo.

Sea como fuere, lo cierto es que en los documentos de los cuatro monasterios escogidos para este trabajo nos encontramos con que cada uno de ellos se vio implicado en una asamblea judicial celebrada en sendas iglesias episcopales. De tal modo que tenemos constancia de una celebrada en el viejo Mondoñedo ${ }^{52}$, alguna otra en la catedral de $\operatorname{Lugo}^{53} \mathrm{y}$, finalmente, dos casos que tuvieron como marco la iglesia de Santiago.

Esas dos asambleas judiciales celebradas en el loco apostolico compostelano se celebraron en el tramo final del siglo x. Una de ellas, notificada en un documento de Sobrado, datada en el ańo $992^{54}$ y otra registrada en un diploma de Celanova y que tuvo lugar unos años antes, en el 985, en este caso ante la curia regia ${ }^{55}$.

Es posible que este lugar concentrara ceremonias de especial significado y solemnidad debido a la creciente importancia religiosa y política de la Iglesia de Santiago en este siglo ${ }^{56}$, al tiempo que los juramentos realizados en presencia de una reliquia de tan gran valor, como era el supuesto cuerpo íntegro de un apóstol de Cristo, contarían con una dosis especial de sacralidad. A este respecto, y aunque perteneciente al Tumbo A, cartulario confeccionado en la propia Iglesia de Santiago a principios del siglo XII, parece pertinente mencionar un documento que recoge un famoso pleito datado en el año $961^{57}$.

Dicho conflicto está protagonizado por dos de los más importantes obispos de la Galicia del siglo x, pero, sin embargo, tiene una evidente relación, debido a la identidad

52 TL, doc. 207, pp. 258-259.

53 TS, doc. 145, pp. 306-307.

54 TSob, doc. 130, pp. 163-165.

55 Tale placitum roboramus in concilio in presentia regis et omne concilium in Sancto Iacobo; TC, doc. 507, pp. 701-702.

56 López Alsina, Fernando. La ciudad de Santiago de Compostela en la Alta Edad Media. Santiago de Compostela: Ayuntamiento de Santiago de Compostela, 1988, pp. 147-154 y 174-186 y «Cabeza de oro refulgente de España: los orígenes del patrocinio jacobeo sobre el reino astur». En RUIZ DE LA Peña Solar, Juan Ignacio (coord.). Las peregrinaciones a Santiago de Compostela y San Salvador de Oviedo en la Edad Media: actas del Congreso Internacional celebrado en Oviedo del 3 al 7 de diciembre de 1990. Oviedo: Gobierno del Principado de Asturias, 1993, pp. 27-36.

57 Lucas Álvarez, Manuel. Tumbo A de la catedral de Santiago. Santiago de Compostela: Seminario de Estudos Galegos, 1998, doc. 42, pp. 114-116. Se trata de un documento bastante conocido y que ha sido, incluso, objeto de algún estudio monográfico; BouZa BreY, Fermín. «La prueba judicial del juramento sobre el sepulcro del Apóstol». Compostellanum, 1959, vol. 4, n. ${ }^{2}$ 2, pp. 333-337. 
BAÑOS, CLAUSTROS Y PIEDRAS: UNA APROXIMACIÓN A LOS ESCENARIOS DE LAS ASAMBLEAS JUDICIALES EN LA GALICIA ALTOMEDIEVAL JOSÉ MIGUEL ANDRADE CERNADAS

de los propios contendientes, con el mundo monástico. Se trata de Rosendo ${ }^{58}$, obispo de Dumio, fundador y figura clave del monasterio de Celanova, y Sisnando II de Iria ${ }^{59}$, promotor, junto a sus padres y hermano, del primer monasterio de Sobrado ${ }^{60}$.

El motivo de la querella es la posesión de unas pesqueras en el territorio de Postmarcos. Arranca el documento recordando la donación del condado de Postmarcos a la iglesia de Santiago, en cuyo territorio se incluían las pesqueras cuya producción y propiedad también pertenecían a Santiago. Tras este párrafo introductorio, el redactor del documento da un giro al relato pasando a centrarse en el inicio del pleito entre estos dos contendientes usando, para ello, la fórmula inicial accidit contentio. Dicho arranque tuvo como escenario el locum Sancte Eulalie Hiriensis sedis ${ }^{61}$. Se entiende, en consecuencia, que la primera fase del pleito se sustanció en la todavía sede catedralicia iriense. El documento se hace eco ahora de las declaraciones de los dos obispos. Rosendo decía que la cuarta parte de dichas salinas habían pertenecido a su madre Ilduara, quien las había recibido en donación de Ramiro II, teniéndolas hasta su muerte sin ningún impedimento. Sisnando, por su parte, responde en estilo directo, como si de una alocución reproducida se tratase, argumentando que pertenecían a su sede desde el tiempo de su antecesor el obispo Hermenegildo íntegras y tal y como consta en documento. Posteriormente, insiste, pasaron a su propiedad. En ambos casos, esas pesqueras habían sido íntegramente de Santiago in facie, primero, de Ilduara y después de San Rosendo ${ }^{62}$.

El pleito se traslada al monasterio de Guimarães, en Portugal, fundado por esos mismos tiempos por la poderosa condesa Mumadona ${ }^{63}$, en donde se continúa ante omnes magnati. Es allí donde debió decidirse que el siguiente paso a dar en la resolución del pleito tendría que ser el juramento. Pero el lugar en el que debía ser pronunciado no era cualquiera. Se designa, como escenario de un ritual que, con toda la impropiedad, vamos a definir como ordalía por el juramento, la Iglesia de Santiago y, más concretamente, el edículo en el que, según la tradición, reposaban los restos del apóstol Santiago. San Rosendo designa como sus testigos/juradores a dos presbíteros y a dos laicos, para que preberent sacramentum in tumulum Beati Iacobi apostoli et firmarent secundum ipse pater domnus Rudesindus episcopus dicebat. También Sisnando designa a sus homines bonos

58 La bibliografía sobre este personaje es muy abundante. Como corolario de parte de los estudios más recientes, ver Rudesindus. San Rosendo. Su tiempo y su legado. Congreso Internacional: Mondoñedo, Santo Tirso (Portugal) y Celanova, 27-30 de junio de 2007. Santiago de Compostela: Consellería de Innovación e Industria, 2009.

59 Portela Silva, Ermelindo. «El rey y los obispos. Poderes locales en el espacio galaico durante el periodo astur». Territorio, Sociedad y Poder, 2009, vol. 2, pp. 215-226; Baliñas Pérez, Carlos. Gallegos del año Mil. A Coruña: Fudación Pedro Barrié de la Maza,1998, pp. 177-229.

60 Pallares Méndez, El monasterio, pp. 70-111.

61 Lucas Álvarez, Tumbo A, p. 115.

62 Ibidem.

63 Monasterio y personaje que tenían un evidente prestigio. No es, de hecho, esta la única ocasión en que un pleito originado en el territorio de la actual Galicia viene a resolverse (o a ser consultado) en Guimarães y con doña Mummadona. Es el caso, por ejemplo, del famoso diácono Odoino y uno de sus varios pleitos. TC, doc. 265, pp. 377-385. Sobre Guimarães, al menos desde el punto de vista de las referencias documentales de su importancia, ver MARQues, Da representaçáo, pp. 245-251. 
BAÑOS, CLAUSTROS Y PIEDRAS: UNA APROXIMACIÓN A LOS ESCENARIOS DE LAS ASAMBLEAS JUDICIALES EN LA GALICIA ALTOMEDIEVAL JOSÉ MIGUEL ANDRADE CERNADAS

ueridicos, un diácono y cuatro laicos, con la misma obligación de jurar sobre el sepulcro de Santiago ${ }^{64}$.

Es decir, ante la especie de callejón sin salida que se plantea en este pleito, se recurre al juramento en la iglesia más importante de Galicia y sobre el sepulcro que se consideraba como propio del Apóstol. Ante esta tesitura la parte de San Rosendo se allana, reconociendo la veracidad del planteamiento de Sisnando-Iria y queriendo evitar jurar en falso: retrouerterunt se de hoc iuramento, nolentes iurare, quia timebant falsun dixisse. De todos modos, pese a ello, los testigos de la parte de Sisnando, a instancias de la asamblea judicial y para ratificar la veracidad de su testimonio, entran en el túmulo de Santiago et dederunt sacrum iuramentum per ipsius corpus Apostoli ${ }^{65}$, depositando sobre el sepulcro los documentos de la pesquera y confirmando, de un modo tan palmario, teatral y sacral, la plena posesión de esas pesqueras, tal y como había defendido Sisnando, por parte de la Iglesia de Santiago.

Regresando a la documentación monástica hay que señalar que los propios monasterios son otro de los escenarios predilectos para la celebración de asambleas judiciales. De los ejemplos que hemos estudiado hay dos que presentan realidades muy distintas. El primer caso es el representado por Sobrado. La documentación conservada de fecha anterior a la fundación del monasterio permite conocer, como ya se comentó antes, el archivo condal de los condes de Présaras, Hermenegildo y Paterna. Varios de esos documentos de la primera mitad del $\mathrm{x}$ nos muestran a los condes en relación con la actividad jurisdiccional y beneficiándose de ella. Así, por ejemplo, los vemos recibiendo bienes por plácitos incumplidos ${ }^{66}$, incorporando nuevas propiedades como resultado de transacciones judiciales ${ }^{67}$ o como compensación por préstamos impagados ${ }^{68}$. En otros, su participación jurisdiccional se hace más explícita como cuando los vemos presidiendo, junto a los jueces, las asambleas judiciales que tratan de resolver determinados pleitos ${ }^{69}$. Aunque solo se especifique en un documento ${ }^{70}$, hemos de dar por supuesto que esta actividad judicial tiene como escenario preferente la casa de Sobrado en la que residen ${ }^{71}$ y sobre la que, poco después, se edificará el monasterio familiar de Sobrado ${ }^{72}$. Sin embargo, los documentos con información judicial de la época del cenobio familiar no nos permiten certificar que Sobrado siguiera siendo emplazamiento de asambleas y actividades de tipo jurídico $^{73}$, si bien no podemos descartarlo rotundamente.

64 Lucas Álvarez, Tumbo A, p. 115.

65 Ibidem.

66 TSob, doc. 31, p. 62.

67 TSob, doc. 23, pp. 55-56.

68 TSob, doc. 98, p. 121.

69 TSob, doc. 103, pp. 123-124.

70 Ibidem.

71 Adducti fuimus igitur in presentia uestra et iudicum hic in Superato; Ibidem.

72 Pallares Méndez, M. ${ }^{a}$ del Carmen y Portela Silva, Ermelindo. «Para una lectura histórica del paisaje. La impronta medieval». En Pereira Menaut, Gerardo y Portela Silva, Ermelindo (eds.). El territorio en la historia de Galicia. Organización y control. Siglos I-XXI. Santiago de Compostela: Universidade de Santiago de Compostela, 2015, pp. 115-117.

73 Los documentos de este período o bien carecen de información sobre el emplazamiento de los pleitos y asambleas mencionados o nos remiten a lugares que no son Sobrado, como Santiago, Marzoa o Pezobre. 
BAÑOS, CLAUSTROS Y PIEDRAS: UNA APROXIMACIÓN A LOS ESCENARIOS DE LAS ASAMBLEAS JUDICIALES EN LA GALICIA ALTOMEDIEVAL JOSÉ MIGUEL ANDRADE CERNADAS

El segundo caso, de cariz completamente distinto, lo representa el monasterio de Celanova. En cuatro de los 24 documentos judiciales de este monasterio en los que se menciona algún emplazamiento, esa ubicación es, precisamente, el propio cenobio. Dos de ellos, datados en los años 1007 y $1008^{74}$, están relacionados con el bien documentado y estudiado prepósito celanovense Cresconio ${ }^{75}$. Se trata de sendas ocasiones en que este monje lleva a juicio a personas que, siempre según su punto de vista, han incumplido ventas acordadas previamente con él. Ambos juicios se celebran in presentia iudicum, hic in monasterio ${ }^{76}$, dándose la particularidad de que en ambos casos se menciona a los mismos agentes legales ${ }^{77}$. Estos dos ejemplos permitirían plantearse si otros documentos, que nos remiten a incorporaciones patrimoniales del monasterio previo juicio o intervención judicial, habrían tenido su emplazamiento en el propio monasterio ${ }^{78}$.

El tercer caso es un poco más complejo. Se trata de un pleito que, en 1012, enfrentó a una persona llamada Vistrario con Celanova a propósito de una villa próxima a la actual parroquia de San Pedro de Mezquita ${ }^{79}$. Es uno de esos casos, previamente comentados, en que el proceso se inicia y se tramita ante el rey, en este caso -como en otros tantos de este cenobio-Alfonso V. El monarca ordena a su sayón que incaute la villa en disputa, mientras se produce la primera actuación judicial; esta tiene lugar en Baños de Molgas, tal y como se comentó previamente.

La segunda de las «instancias», la de la exposición de los testigos de las partes, se produjo en un monasterio, el de San Martiño de Pazó, no muy lejano de la villa termal en que el rey había dado inicio al proceso. Esta exposición de los testimonios no solo se hizo en este cenobio sino teniendo a sus monjes como espectadores y testigos de esta parte del proceso $^{80}$. Inmediatamente a continuación, según el relato del redactor del documento, Vistrario se allana y reconoce que la razón le corresponde a Celanova. No acaba aquí el relato, sino que se hace mención a un nuevo acto público en el que Vistrario se somete a la agnitio formal que genera la redacción del documento. Dicho acto se lleva a cabo coram omni concilio hic in monasterio Cellenove ${ }^{81}$.

El último documento en el que, de modo explícito, Celanova es mencionada como ámbito de celebración de intervenciones judiciales, y en este caso por partida doble, data del ańo $1012^{82}$. El origen de la historia judicial está en un pleito que trata la acusación de Gunderigo Dadilaz contra el matrimonio formado por Daildo y Teodila por el rauso

74 TC, docs. 193 y 194, pp. 269-271.

75 Carzolio de Rossi, M. ${ }^{a}$ Inés. "Cresconio, prepósito de Celanova. Un personaje gallego al filo del siglo XI». Cuadernos de Historia de España, 1973, vol. 57-58, pp. 225-279.

76 TC, doc. 194, p. 271.

77 Como juez se menciona a otro prepósito, don Munio, si bien en el primero de estos dos casos se habla, igualmente, de aliorum iudicum; el merino es don Sandino y el sayón es Sigila.

78 Ver los comentarios de F. Luis Corral sobre las características e implicaciones de los pleitos que, celebrados en un monasterio, tenían al cenobio, a la vez, como una de las partes implicadas; Luis Corral, «Lugares».

79 TC, doc, 548, pp. 756-757.

80 Hic in monasterio Palatiolo et fratribus ibi abitantibus; Ibidem.

81 Ibidem.

82 TC, doc. 572, pp. 789-791. 
BAÑOS, CLAUSTROS Y PIEDRAS: UNA APROXIMACIÓN A LOS ESCENARIOS DE LAS ASAMBLEAS JUDICIALES EN LA GALICIA ALTOMEDIEVAL JOSÉ MIGUEL ANDRADE CERNADAS

sufrido por la hija del demandante ${ }^{83}$. El procedimiento es iniciado por los sayones del rey Alfonso $\mathrm{V}$ y el conde Rodrigo Ordóñez que omnem terram Limie iuri suo obtinebat $t^{84}$. El juicio es iniciativa, en consecuencia, de la justicia regia, aunque se celebró in concilio monasterio Cellenove in presentia iudices, entre los que se menciona al propio abad celanovense, Aloito, a uno de los prepósitos monásticos y a un tercer juez ${ }^{85}$.

La familia demandada fue condenada a un pago como pena por la comisión del delito por el que habían sido juzgados. Como no pueden abonar ese importe, es el propio monasterio de Celanova el que lo satisface y, de ese modo, los libera ${ }^{86}$. Entonces Daildo y Teodila entregan al monasterio una propiedad a modo de compensación ${ }^{87}$. Sin embargo, no acaba aquí la historia tal y como nos la transmite el narrador documental. El abad Aloito deja Celanova para ocuparse de la restauración de San Pedro de Rocas, ocasión que aprovechan Daildo y su esposa para volver a hacerse con el control de la villa $\mathrm{y}$, consiguientemente, tulivimus ea de iuri monasterio et plegavimus iuri nostro extra veritate $e^{88}$. Esta acción provoca una nueva intervención que conduce a este matrimonio a otra asamblea judicial celebrada en el mismo monasterio con un protagonismo aún mayor de los agentes monásticos ${ }^{89}$ y que acaba con una nueva condena más dura que la anterior: $e t$ hordinavit vobis lex gotica et veritate ut duplassemus ipsa villa ${ }^{90}$. Así pues, y en un mismo documento, vemos al monasterio de Celanova sirviendo como escenario de una asamblea judicial surgida a iniciativa de la justicia real y como marco de otra en la que los intereses del monasterio se mezclan con sus funciones judiciales.

En la documentación gallega de la Alta Edad Media no es fácil encontrar, por el contrario, procedimientos judiciales que se celebren al aire libre. En el estado actual de nuestro conocimiento, no tenemos constancia de juicios o asambleas celebrados en el mallum publicum de aldeas o pueblos como ocurre en Cataluña ${ }^{91}$. Tampoco podemos certificar, al menos de momento, realidades semejantes a los hanging promontories o los moots de la Inglaterra anglosajona ${ }^{92}$, ámbitos de celabración al aire libre de reuniones públicas de naturaleza judicial y política. Hay un único tipo de casos en que buena parte del procedimiento, y una porción sustantiva del relato documental, se desarrolla al aire libre. Me refiero, claro está, a las disputas por límites que se resuelven con una pesquisa perambulatoria.

83 Pro peccato impendiente quod nobis evenit et rausavimus filis de ipse Gunderigo et postea calumniaverunt nos pro tale actio; Ibídem, p. 789.

84 Ibidem.

85 Vos iamdicti domni Aloiti abbati et preposito Gutier Nuniz et Ero Sarraciniz; Ibidem, p. 790.

86 Et pariastis pro nos et eiecistis nos de illorum manuum et de suo ligamine; Ibidem.

87 Et dedimus vobis pro ipsum ganatum ipsa villa de Domenzi et obtinuistis ea iure quieto post parte monasterii; Ibidem.

88 Ibidem.

89 Ad veritate in concilio monasterii Cellenove in presentia iudice et preposito Ziti Donon; Ibidem.

90 Ibidem.

91 Salrach, Justícia, p. 31.

92 Sobre los primeros Baker, John y Brookes, Stuart. «Monumentalising the political landscape: a special class of Anglo-Saxon assembly site». The Antiquaires Journal, 2013, vol. 93, pp. 147162. Sobre los segundos, BAKER y Brookes, «Identifying», pp. 3-4. 
BAÑOS, CLAUSTROS Y PIEDRAS: UNA APROXIMACIÓN A LOS ESCENARIOS DE LAS ASAMBLEAS

JUDICIALES EN LA GALICIA ALTOMEDIEVAL JOSÉ MIGUEL ANDRADE CERNADAS

Veamos uno de los muchos ejemplos que podrían escogerse. En el año 950, San Rosendo, obispo de Dumio y fundador del recientemente creado monasterio de Celanova, solicita la intervención del rey Ramiro II $^{93}$. El motivo de la petición de Rosendo tenía que ver con la villa de sancto Felice, quod superadito vocabulo dicitur Baronceli, es decir la actual parroquia de San Fiz de Pazos en el concello de Verín ${ }^{94}$. Se quejaba el obispo de que los hombres de las villae limítrofes con la de San Fiz, no respetaban los límites de la misma. Recurriendo a una indicación topográfica poco habitual en la documentación gallega, el redactor del documento especifica que las villae y los hombres que molestan e inquietan la propiedad rosendiana son, por la parte occidental los de Vilazá y Albarellos y los de Santa María por la parte oriental ${ }^{95}$. Por ello, Rosendo solicita del rey que, del palacio, diera previsores veridicos que delimitaran, con justicia y precisión, los límites de todas esas aldeas tal y como eran desde tiempo antiguo y tal y como deberían de estar delimitadas físicamente.

De ahí el documento, de claro carácter narrativo, nos traslada al escenario de la disputa. Nos cuenta cómo vinieron ibidem un grupo de ducibus vel proceres palatii, de los cuales seis, entre los que están el obispo auriense Diego y dos condes, se mencionan por sus nombres, acompañados por aliorum bonorum hominum non modica multitudi$n e^{96}$. Esta parte anónima y «multitudinaria» de la comisión pesquisidora estaba formada, seguramente, por gente local. Podemos pensar, aunque aquí no se mencionen expresamente, en personas de edad avanzada, depositarias de la memoria colectiva y a las que se solía recurrir en circunstancias de esta naturaleza, así como en prohombres locales que, de modo creciente, parecen estar asumiendo funciones de intermediación entre los poderosos y las comunidades campesinas ${ }^{97}$. Esta comisión realiza una pesquisa a pie de campo verificando los límites de los espacios en disputa. Dichos límites están marcados por accidentes naturales, monumentos del pasado, o límites artificiales que son identificados con detalle.

Más de un siglo después, este tipo de disputas por límites se sigue realizando de un modo semejante. En algún caso los documentos nos indican el lugar en el que los pesquisidores se reúnen para iniciar su perambulación y, en ocasiones, para jurar que van a actuar correctamente. Tal es el caso de un pleito entre los monasterios de Samos y el de Barxa, cuyo documento es fechado por Manuel Lucas entre los años 1074 y $1087^{98}$ y en

93 TC, doc. 93, pp. 141-144.

94 Este documento ha sido estudiado, con detalle, por varios autores. A destacar los planteamientos, muy centrados en los datos que nos ofrece para hacer una historia de la organización del espacio y de la delimitación de la red de villae en la Galicia altomedieval, de Pallares y Portela; Pallares Méndez y Portela Silva, «Para una lectura», pp. 104-109.

95 TC, doc. 93, p. 142.

96 Ibidem.

97 Martínez Sopena, Pascual. «La justicia en la época astur-leonesa: entre el Liber y los mediadores sociales». En Rodríguez, Ana (ed.). El lugar del campesino. En torno a la obra de Reyna Pastor. València: Universitat de València, 2007, p. 249. Más recientemente son de tener en cuenta los interesantes comentarios y matices que, sobre los boni homines, podemos leer en uno de los últimos trabajos de Álvaro Carvajal; Carvajal Castro, «Meeting».

98 TS, doc. 45, pp. 141-142. 
BAÑOS, CLAUSTROS Y PIEDRAS: UNA APROXIMACIÓN A LOS ESCENARIOS DE LAS ASAMBLEAS JUDICIALES EN LA GALICIA ALTOMEDIEVAL JOSÉ MIGUEL ANDRADE CERNADAS

el que uno de los procedimientos consiste en reconstruir los dextros de Samos en tiempos de Alfonso V. El encargado de llevar a cabo la investigación es el obispo Gonzalo, quien realiza una búsqueda de tres días para localizar ancianos y otro tipo de sapitores ${ }^{99}$. Finalmente los convoca en un lugar preciso al aire libre para que den veracidad de su testimonio. En palabras del redactor del documento: Et die sabbati iuncti fuimus ibi in Calvor ad illa petra fita, que illos terminos determinat de antiquis temporibus et dederunt de parte Samanos testamentum quod fecit serenissimus rex Veremudus ad confirmandos dextros et devotionem avorum et parentum suorum ${ }^{100}$. Es un caso semejante a otro documento, prácticamente contemporáneo, procedente del fondo documental de Melón recientemente reeditado y estudiado ${ }^{101}$. Se trata, como en el caso de Samos, de una disputa por límites, si bien en este caso protagonizada por sendas comunidades de la Galicia meridional. Como en el ejemplo precedente, nos encontramos con una referencia a la celebración de un juramento colectivo en un lugar, al aire libre, antes de empezar la pesquisa perambulatoria y en la que, a diferencia del caso samonense, los pies de los testigos juramentados son expresamente mencionados ${ }^{102}$.

La petra fita de Calvor, de la que se habla en el documento samonense, coincide, con toda probabilidad, con el mismo lugar en el que pocos años después el abad Pedro le sale al encuentro al rey Alfonso VI. El monarca iba de camino a Compostela, lo que aprovecha el abad para presentarle un documento que podría poner fin a un enconado conflicto que había mantenido con dos poderosos aristócratas a propósito de la propiedad de una villa: Et venit ille rex ad Sanctum Iacobum et apparuit predictus abbas cum ipso testimonio coram eo ad Petram de Calvor ${ }^{103}$.

Es decir, una misma piedra, seguramente singular y singularizada por el redactor del último documento, sirve como hito de delimitación del perímetro de Samos ${ }^{104}$, lugar de juramentación pública y escenario, ubicado en una vía también singular, de especial significado simbólico y social.

99 Et pergimus ad illam terram et demorati fuimus ibi feria IVta et feria $V^{\text {at }}$ et feria VIa et invenimus ibi homines vivos de tempore domni Adefonsi regis et perexquisivimus quanto plus potuimus et invenimus sapitores, qui viderant Varzena tenere ad domna Ermesinda de manu Mandini abbatis; Ibidem. Sobre este documento y el recurso a los ancianos ver Andrade Cernadas, José Miguel. «La voz de los ancianos. La intervención de los viejos en los pleitos y disputas en la Galicia medieval». Hispania, 2012, vol. 72, n. ${ }^{\circ} 240$, pp. $17-18$.

100 Ibídem.

101 Bermejo Barrera, José Carlos y Romaní Martínez, Miguel. «Et per ubi posueritis vestros pedes iurare. La cojuración y el posible uso de los signos podomorfos en la Galicia medieval y moderna». Madrider Mitteilungen, 2014, vol. 55, pp. 560-595.

102 Que ponant suos pedes per ipsam hereditatem et strement illam de ipsa de Canedelo... Et per ubi posueritis vestros pedes iurare cum XII...; Ibidem. Aunque en este documento no hay mención expresa a piedras de reunión o junto a las que se pronuncian juramentos, los autores dan una serie de noticias sobre la relación existente entre juramentos y piedras desde el mundo antiguo y en distintos lugares del Occidente medieval; Ibidem, pp. 584-585.

103 TS, doc. 145 , p. 307.

104 Arias Cuenllas, Maximino. Historia del monasterio de San Julián de Samos. Samos: Monasterio de Samos, 1992, p. 122. 
BAÑOS, CLAUSTROS Y PIEDRAS: UNA APROXIMACIÓN A LOS ESCENARIOS DE LAS ASAMBLEAS JUDICIALES EN LA GALICIA ALTOMEDIEVAL JOSÉ MIGUEL ANDRADE CERNADAS

El uso simbólico y delimitador de piedras especiales o monumentalizadas ${ }^{105}$ es tema enjundioso y no exento de puntos de vista contrapuestos ${ }^{106}$. Parece probable, en cualquier caso, que hayan jugado un papel referencial como punto de encuentro de las partes litigantes, escenario del inicio de los apeos y posible marco de los juramentos o compromisos previos de los mismos. Son, en consecuencia, hitos a considerar a la hora de estudiar los lugares por donde transcurrió la actividad judicial de la Galicia altomedieval.

\section{REFERENCIAS BIBLIOGRÁFICAS}

Andrade Cernadas, José Miguel. «La voz de los ancianos. La intervención de los viejos en los pleitos y disputas en la Galicia medieval». Hispania, 2012, vol. 72, n. ${ }^{\circ}$ 240, pp. 11-34.

Andrade Cernadas, José Miguel. «Los modelos monásticos en Galicia hasta el siglo XI». Archivo Iberoamericano, 2005, vol. 65, n. ${ }^{\circ}$ 252, pp. 587-609.

Andrade Cernadas, José Miguel. "Villas regias y asambleas judiciales entre los siglos x y xi: el caso de Larín». Signum, 2011, vol. 12, n. ${ }^{\circ}$ 2, pp. 18-35.

Andrade Cernadas, José Miguel. O Tombo de Celanova: estudio introductorio, edición e indices (ss. IX-XII). 2 vols. Santiago de Compostela: Consello da Cultura Galega, 1995.

Arias Cuenllas, Maximino. Historia del monasterio de San Julián de Samos. Samos: Monasterio de Samos, 1992.

BAKer, John y Brookes, Stuart. «Identifying outdoor assembly sites in early medieval England». Journal of Field Archaeology, 2015, vol. 40-41, pp. 3-21.

BaKer, John y Brookes, Stuart. "Monumentalising the political landscape: a special class of Anglo-Saxon assembly site». The Antiquaires Journal, 2013, vol. 93, pp. 147-162.

Baliñas Pérez, Carlos. Gallegos del año Mil. A Coruña: Fudación Pedro Barrié de la Maza,1998.

Bermejo Barrera, José Carlos y Romaní Martínez, Miguel. «Et per ubi posuerintis vestros pedes iurare. La cojuración y el posible uso de los signos podomorfos en la Galicia medieval y moderna». Madrider Mitteilungen, 2014, vol. 55, pp. 560-595.

Bouza Brey, Fermín. «La prueba judicial del juramento sobre el sepulcro del Apóstol». Compostellanum, 1959, vol. 4, n. ${ }^{\circ}$ 2, pp. 333-337.

Carvajal Castro, Álvaro. "Meeting and meeting places in Early Medieval Leon». Early Medieval Europe, 2017, vol. 25-2, pp. 186-207.

Carzolio de Rossi, M. ${ }^{a}$ Inés. «Cresconio, prepósito de Celanova. Un personaje gallego al filo del siglo XI». Cuadernos de Historia de España, 1973, vol. 57-58, pp. 225-279.

Davies, Wendy. Windows on Justice in Northern Iberia, 800-1000. Farnhan: Ashgate, 2016.

Escalona Monge, Julio y Martín Viso, IÑaki. «Los palatia, puntos de centralización de rentas en la meseta del Duero (siglos IX-Xi)». En Vigil-Escalera Guirado, Alfonso; Bianchi, Giovanna y Quirós Castillo, Juan Antonio (eds.). Horrea, barns and silos. Storage and incomes in Early Medieval Europe. [Bilbao]: Universidad del País Vasco, 2013, pp. 103-126.

105 Que pueden ser reminiscencias arqueológicas de épocas anteriores a la de nuestro estudio (megalítica, castrexa, romana...) o, simplemente, piedras o rocas singulares por cualquier razón física o por su mera ubicación referencial.

106 Ferro Couselo, Xesús. Los petroglifos de término y las insculturas rupestres de Galicia. Orense: [s. n.], 1952; García Quintela, Marco Virgilio y Santos Estévez, Manuel. Santuarios de la Galicia céltica: arqueología del paisaje y religiones comparadas en la Edad del Hierro. Madrid: Abada, 2008, en especial pp. 297-322; García Quintela, Marco Virgilio y Seoane Veiga, Yolanda. «La larga vida de dos rocas orensanas». Archivo Español de Arqueología, 2011, vol. 84, pp. 243-266. 
BAÑOS, CLAUSTROS Y PIEDRAS: UNA APROXIMACIÓN A LOS ESCENARIOS DE LAS ASAMBLEAS JUDICIALES EN LA GALICIA ALTOMEDIEVAL JOSÉ MIGUEL ANDRADE CERNADAS

Fernández del Pozo, José M. ${ }^{a}$. Alfonso V (999-1028); Vermudo III (1028-1037). Burgos: La Olmeda, 1999.

Ferro Couselo, Xesús. Los petroglifos de término y las insculturas rupestres de Galicia. Orense: [s. n.], 1952.

Freire Camaniel, José. El monacato gallego en la Alta Edad Media. 2 vols. A Coruña: Fundación Pedro Barrié de la Maza, 1998.

García de Cortázar, José Ángel y Peña Bocos, Ester. «El palatium, símbolo y centro de poder en los reinos de Navarra y Castilla a lo largo de los siglos x a XII». Mayurqa, 1989, vol. 22, n. ${ }^{\circ} 1$, pp. 281-296.

García Quintela, Marco Virgilio y Santos Estévez, Manuel. Santuarios de la Galicia céltica: arqueología del paisaje y religiones comparadas en la Edad del Hierro. Madrid: Abada, 2008.

García Quintela, Marco Virgilio y Seonne Veiga, Yolanda. «La larga vida de dos rocas orensanas». Archivo Español de Arqueología, 2011, vol. 84, pp. 243-266.

Gil Fernández, Juan; Moralejo Álvarez, José L. y Ruiz de la Peña, Juan Ignacio. Crónicas Asturianas. Oviedo: Universidad de Oviedo, 1985.

González Soutelo, Silvia. El valor del agua en el mundo antiguo. Sistemas hidráulicos y aguas mineromedicinales en el contexto de la Galicia romana. A Coruña: Fundación Barrié de la Maza, 2011.

Gutiérrez González, José Avelino y Miguel Hernández, F. «Génesis del urbanismo en la ciudad de León y su transformación en la Edad Media». En Valdés Fernández, Fernando (coord.). La Península Ibérica y el Mediterráneo entre los siglos XI y XII. El urbanismo de los estados peninsulares. Aguilar de Campoo: Fundación Santa María la Real, 1999, pp. 43-90.

Isla Frez, Amancio. Realezas hispánicas del año Mil. Sada-A Coruña: Ediciós do Castro, 1999.

Kозто, Adam J. «Sicut mos esse solet: documentary practices in Christian Iberia, c. 700-1000». En Brown, Warren C. et alii (eds.). Documentary Culture and the Laity in the Early Middle Ages. Cambridge: Cambridge University Press, 2013, pp. 259-281.

Labarge, Margaret Wade. Viajeros medievales: los ricos y los insatisfechos. Madrid: Nerea, 1992.

López Alsina, Fernando. «Cabeza de oro refulgente de España: los orígenes del patrocinio jacobeo sobre el reino astur». En RuIz de la PeÑa Solar, Juan Ignacio (coord.). Las peregrinaciones a Santiago de Compostela y San Salvador de Oviedo en la Edad Media: actas del Congreso Internacional celebrado en Oviedo del 3 al 7 de diciembre de 1990. Oviedo: Gobierno del Principado de Asturias, 1993, pp. 27-36.

López Alsina, Fernando. "Millas in giro ecclesie: el ejemplo del monasterio de Samos». Estudos Medievais, 1993, vol. 10, pp. 159-187.

López Alsina, Fernando. La ciudad de Santiago de Compostela en la Alta Edad Media. Santiago de Compostela: Ayuntamiento de Santiago de Compostela, 1988.

Loscertales, Pilar. Tumbos del monasterio de Sobrado de los Monjes. 2 vols. Madrid: Ministerio de Cultura, 1976.

Lucas Álvarez, Manuel. El Tumbo de San Julián de Samos (Siglos VIII-XII). Estudio introductorio, edición diplomática, apéndices e indices. Santiago de Compostela: Caixa Galicia, 1986.

Lucas Álvarez, Manuel. Tumbo A de la catedral de Santiago. Santiago de Compostela: Seminario de Estudos Galegos, 1998.

Luis CoRral, Fernando. «Lugares de reunión, boni homines y presbíteros en Valdevimbre y Ardón en la Alta Edad Media». Medievalista [em linha], 2015, vol. 18.

Marques, André Evangelista. Da representação documental a materialidade do espaço. Território da diocese de Braga (séculos IX-XI). Porto: Ediçóes Afrontamento, 2014. 
BAÑOS, CLAUSTROS Y PIEDRAS: UNA APROXIMACIÓN A LOS ESCENARIOS DE LAS ASAMBLEAS JUDICIALES EN LA GALICIA ALTOMEDIEVAL JOSÉ MIGUEL ANDRADE CERNADAS

Martínez Sopena, Pascual. «La justicia en la época astur-leonesa: entre el Liber y los mediadores sociales». En Rodríguez, Ana (ed.). El lugar del campesino. En torno a la obra de Reyna Pastor. València: Universitat de València, 2007, pp. 239-260.

Pallares Méndez, M. a del Carmen. El monasterio de Sobrado: un ejemplo del protagonismo monástico en la Galicia medieval. La Coruña: Diputación Provincial, 1979.

Pallares Méndez, M. a del Carmen y Portela Silva, Ermelindo. «Para una lectura histórica del paisaje. La impronta medieval». En Pereira Menaut, Gerardo y Portela Silva, Ermelindo (eds.). El territorio en la historia de Galicia. Organización y control. Siglos I-XXX. Santiago de Compostela: Universidade de Santiago de Compostela, 2015, pp. 97-152.

Pérez de Urbel, Justo. Sampiro. Su crónica y la monarquia leonesa en el siglo X. Madrid: Consejo Superior de Investigaciones Científicas, 1952.

Portela Silva, Ermelindo. «El rey y los obispos. Poderes locales en el espacio galaico durante el periodo astur». Territorio, Sociedad y Poder, 2009, vol. 2, pp. 215-226.

Reilly, Bernard F. El Reino de León y Castilla bajo el rey Alfonso VI: 1065-1109. Toledo: Consejo Superior de Investigaciones Científicas, 1989.

Rodríguez González, Ángel y Rey Caiña, José Ángel. «El Tumbo del monasterio de Villanueva de Lorenzana». Estudios Mindonienses, 1992, vol. 8, pp. 11-324.

Rodríguez Míguez, Luis. Estudio histórico bibliográfico del termalismo: principales urgencias de la provincia de Orense. Orense: Diputación Provincial 1995.

Rudesindus. San Rosendo. Su tiempo y su legado. Congreso Internacional: Mondoñedo, Santo Tirso (Portugal) y Celanova, 27-30 de junio de 2007. Santiago de Compostela: Consellería de Innovación e Industria, 2009.

Salrach, Josep M. ${ }^{a}$. Justícia i poder a Catalunya abans de l'any mil. Vic: Eumo, 2013.

Sánchez-Albornoz, Claudio. Una ciudad de la España cristiana hace mil años. 14. ${ }^{a}$ ed. Madrid: Rialp, 1991.

Varela Sieiro, Xaime. Léxico cotián na alta Idade Media de Galicia: a arquitectura civil. Santiago de Compostela: Universidade de Santiago de Compostela, 2008.

Viñayo, Antonio. Fernando I, El Magno (1035-1065). Burgos: La Olmeda, 1999.

Zwanzig, Christofer. "Heidenheim and Samos: Monastic Remembrance of the 'Anglo-Saxon Mission' in Southern Germany and the 'Mozarabic Resettlement' of Northern Spain Compared». En Sánchez Pardo, José C. y Shapland, Michael G. (eds). Churches and Social Power in Early Medieval Europe. Integrating Archaeological and Historical Approaches. Turnhout: Brepols, 2015, pp. 269-295. 